\title{
Income and Employment Among Homeless People: The Role of Mental Health, Health and Substance Abuse
}

\author{
Samuel H. Zuvekas* and Steven C. Hill \\ Center for Cost and Financing Studies, Agency for Healthcare Research and Quality, 2101 East Jefferson Street, Ste. 500, Rockville, MD 20852, USA
}

\begin{abstract}
Background: The homeless population is among the poorest of the poor in the United States. Employment and government programs are potential sources of income, but many homeless people face potential barriers to work: many have serious mental and physical disabilities, and many more have alcohol and drug disorders. As a result, most homeless who work do so either for a few hours per day or only some days, which provides little income. General Assistance, a public program of last resort, also provides a low level of income support. More income might be gained through higher levels of work or participation in income support programs for people with disabilities.

Aims of the Study: To investigate the characteristics of homeless people that impede them in the labor market and in government program participation, paying particular attention to their mental and physical health, as well as their alcohol and drug problems.

Data: Data are from a survey of the homeless population in Alameda County, California, conducted from 1991 to 1993. Our sample is 471 homeless adults randomly selected from area shelters and meal providers, who were reinterviewed approximately 6 months later, regardless of domiciliary status. Mental health and substance use problems were assessed using the Diagnostic Interview Schedule, a structured, psychiatric interview that uses criteria based on the American Psychiatric Association's Diagnostic and Statistical Manual of Mental Disorders 3rd edn (revised). Employment between the first and second interview is categorized as none, low level (less than 6 hours a day or fewer than half the days between interviews) or higher level (at least 6 hours a day for at least half the days).

Analytical Procedures: The models of employment status and program participation are recursive in that homelessness at the first wave of the survey is treated as given. Thus we explore whether, given their initial homelessness, persons can gain or maintain access to income between the two interviews, conditional on the sample member's homelessness, health and disability at the first interview. Using maximum-likelihood methods, we estimate a generalized ordered logit model of whether the person works not at all, at a low level or at a higher level. Participation in disability programs and GA are estimated as probit models over the subsamples of potentially eligible participants.
\end{abstract}

Results: While a surprisingly large number of homeless people

\footnotetext{
* Correspondence to: Sam H. Zuvekas, Center for Cost and Financial Studies, Agency for Health Care Research and Quality, 2101 E. Jefferson St, Ste. 500, Rockville, MD 20852, USA

Tel.: (301)-594-2008.

Fax: (301)-594-2166.

Email address: SZuvekas@AHRQ.gov
}

work, few homeless persons are able to generate significant earnings from employment alone. Physical health problems that limit work or daily activities, in particular, are barriers to employment. Drug and alcohol abuse and dependence are positively associated with lower work level but are negatively related to higher work level. Program participation is quite low relative to eligibility. Those with physical health problems are substantially more likely than those with mental health problems to be in the more generous disability programs. Substance use disorders are also a barrier to participation in disability programs.

Discussion: Mental health, health and disability play a large role in the employment and program participation of the homeless and persons at risk for homelessness. Physical disabilities are a barrier to employment, and those with substance use disorders are most likely to work at lower levels that provide less income. Rates of participation in government programs are low, and people with major mental disorders have especially low participation rate in disability programs. The low rates of participation, particularly in the disability programs, suggest the need for continued research in improving access to income support programs among eligible homeless populations. (C) 2000 John Wiley \& Sons, Ltd.

Received 10 April 2000; accepted 16 November 2000

\section{Introduction}

The homeless population is among the poorest of the poor in the United States. Zlotnick and Robertson ${ }^{1}$ report a median monthly income of $\$ 376$ from a 1991 survey of homeless individuals in California (the one used in this study and described in the next section). This is well below the 1991 monthly poverty line of $\$ 567$ for individuals and compares unfavorably with any domiciled ethnic group or family type in the United States. People who are homeless have several potential sources of income to support themselves: employment, government programs, panhandling and illegal activities. For healthy, educated, nondisabled individuals, employment may be able to provide support, but jobs may be intermittent or have low pay., ${ }^{2,3}$ However, it has been widely reported that many homeless people have serious mental and physical disabilities, and many more have alcohol and drug disorders. ${ }^{4-7}$ Mental illness, alcoholism, drug abuse and poor health have been found to be barriers to employment and earnings in domiciled 
populations. ${ }^{8-11}$ They are also likely to be important barriers to employment and earnings for homeless populations. For the homeless facing barriers to employment, government programs such as the federal disability programs are an important alternative source of monetary support. Panhandling is not likely to be particularly lucrative, and illegal activities are problematic from a policy perspective.

In this paper, we investigate potential sources of income for the homeless population, in particular employment and government transfer programs. We focus on the characteristics that impede homeless people in the labor market and in government program participation, paying particular attention to their mental and physical health, as well as their alcohol and drug problems. Data are from a survey of the homeless population in Alameda County, California, conducted from 1991 to 1993 . We build on two prior analyses of these data. First, Wright ${ }^{3}$ has described the sources of income of the homeless and their association with exiting homelessness. He found that because of low wages and intermittent work, employment was not associated with exits, and receipt of General Assistance (GA) was not associated with exits because of low cash benefits. However, he found the more generous Supplemental Security Income (SSI) program, available to people with disabilities, is associated with exits. Second, Zlotnick and Robertson ${ }^{1}$ examined the relationships between mental, alcohol and drug problems and having any employment and receiving cash benefits from any government program. They found no statistically significant association between these problems and employment, and that people with alcohol and drug problems, but not those with mental health problems, were more likely to receive cash benefits. We expand the analysis of Zlotnick and Robertson to (1) differentiate between participation in GA and participation in SSI, which have different eligibility criteria and benefit levels, (2) differentiate between lower and higher employment levels, because we find only a few homeless people work most days more than 6 hours, and (3) include physical disabilities and health as explanatory variables for employment and program participation.

The paper is organized as follows. We first describe the homeless data, including (1) the prevalence of health, mental health and alcohol and drug problems among the homeless population and (2) sources of income of the homeless. Next, we present estimates from models of employment and public program participation. We find that few homeless people work sufficiently to earn significant amounts of income, and program participation is low relative to eligibility, especially for those with mental disorders. We also find that health problems are barriers to higher employment levels, and alcohol and drug problems are barriers to participation in more generous government transfer programs. In addition, we find that those with physical health problems are substantially more likely than those with mental health problems to be in more generous government transfer programs. We conclude with a discussion of the implications of changes in the federal disability programs and cutbacks in state and local GA programs, particularly for the many homeless persons with alcohol and drug disorders.

\section{Facts About the Homeless: Data Description}

Our data come from a unique three-wave longitudinal survey of homeless individuals in Alameda Country, California, jointly commissioned by the Institute for Research on Poverty at the University of Wisconsin-Madison and the Alcohol Research Group at the University of California at Berkeley and conducted by Berkeley's Survey Research Center. A total of 564 homeless adults from area shelters and meal plans were randomly selected to participate in this survey, which was carried out over an 18-month period beginning in late 1991.* To qualify as homeless, respondents must have stayed in a shelter, on the street, or in some other transitory location at least one night in the 30 days prior to the initial interview. Subsequent interviews were conducted approximately 6 and 12 months later, regardless of domiciliary status. The study achieved a remarkably low level of attrition, given the inherent difficulty in locating homeless persons. Only 16 percent of the sample could not be located for the second-wave interview. $\dagger$

To examine labor force participation and program participation of homeless individuals and the determinants of employment and program participation, we focus on the sample of individuals who were reinterviewed in the second wave. The sample size for these analyses is 471 individuals who were homeless at the time of the first wave. Table 1 presents sample means for the variables described in this section.

\section{Poor Physical and Mental Health and Substance Use Disorders}

Health is represented by indicators from the first wave interview measuring physical health, mental health and substance use or dependence. Poor and fair health are from the standard self-reported health scale. Physical limitations indicates either a self-reported physical health condition that limits work or daily activities or a condition observed by the interviewer. Mental health and substance use problems of homeless persons were assessed using the Diagnostic Interview Schedule (DIS). The DIS is a structured, psychiatric interview that uses criteria based on the American Psychiatric Association's Diagnostic and Statistical Manual of Mental Disorders 3rd edn (revised) (DSM-III-R). ${ }^{13} \neq$ The DIS is

\footnotetext{
* Piazza and Cheng ${ }^{12}$ provide a more detailed description of the sample design for this survey.

$\dagger$ We use a probit model to explore the characteristics associated with attrition (see Appendix Table A). Having a physical health problem that limits work or daily activities, being a man, and being black are characteristics associated with higher rates of attrition. Alcohol and other drug diagnoses, being older, and being homeless with children are associated with less attrition. Having a mother who completed high school and having been in a family that received welfare when the respondent was a child were both associated with less attrition.

$\ddagger$ See Robins et al. ${ }^{14}$ for more information on the DIS
} 
Table 1. Descriptive statistics

\begin{tabular}{|c|c|c|}
\hline Variable & Description & Waves $1-2$ \\
\hline \multicolumn{3}{|c|}{ Employment (between waves 1 and 2) } \\
\hline Higher level & Worked most days and six or more hours/day (indicator) & 0.14 \\
\hline Lower level & Worked less than 50 percent of days or less than six hours/day (indicator) & 0.34 \\
\hline Never worked & Did not work at all between waves 1 and 2 (indicator) & 0.52 \\
\hline \multicolumn{3}{|c|}{ Program participation (between waves 1 and 2) } \\
\hline Disability & Received SSI or SSDI (indicator) & 0.11 \\
\hline GA & Received General Assistance (indicator) & 0.42 \\
\hline AFDC & Received AFDC (indicator) & 0.10 \\
\hline \multicolumn{3}{|l|}{ Human capital (wave 1) } \\
\hline High school & Completed high school (indicator) & 0.72 \\
\hline Technical education & Technical or vocational education (indicator) & 0.43 \\
\hline Communication problem & $\begin{array}{l}\text { Communication problems: illiteracy or great difficulty hearing or understanding } \\
\text { (indicator) }\end{array}$ & 0.29 \\
\hline \multicolumn{3}{|l|}{ Health status (wave 1) } \\
\hline Physical limitation & Physical disability (indicator) & 0.24 \\
\hline Poor health & Self-reported (indicator) & 0.09 \\
\hline Fair health & Self-reported (indicator) & 0.26 \\
\hline Mental health & Major mental disorder (indicator) & 0.23 \\
\hline AODA severe & Alcohol or other drug use disorder, severe (indicator) & 0.54 \\
\hline AODA moderate & Alcohol or other drug use disorder, moderate (indicator) & 0.18 \\
\hline \multicolumn{3}{|l|}{ Childhood experience (wave 1) } \\
\hline Mother's education & Woman who raised respondent completed high school (indicator) & 0.60 \\
\hline Mother's education missing & Missing mother's education (indicator) & 0.12 \\
\hline Parent welfare & Parent(s) ever received any type of welfare while person was under 18 (indicator) & 0.10 \\
\hline Child abuse & Physically or sexually abused as a child (indicator) & 0.22 \\
\hline Juvenile hall & Ever placed in a juvenile hall as a child (indicator) & 0.28 \\
\hline Foster care & Ever placed in foster care or a group home as a child (indicator) & 0.10 \\
\hline \multicolumn{3}{|l|}{ Demographic (wave 1) } \\
\hline Male & (indicator) & 0.76 \\
\hline Black & (indicator) & 0.69 \\
\hline Age & Years at wave 1 interview & 37 \\
\hline With children & Homeless with any children (indicator) & 0.10 \\
\hline Married & (indicator) & 0.09 \\
\hline Prison & Ever in prison (indicator) & 0.18 \\
\hline \multicolumn{2}{|l|}{ Unweighted sample size } & 471 \\
\hline
\end{tabular}

Notes: AFDC $=$ Aid to Families with Dependent Children; AODA = alcohol and other drug abuse; GA = General Assistance; SSI = Supplemental Security Income; SSDI = Social Security Disability Insurance.

used to identify major mental disorders and substance use or dependence. Mental health indicates the presence of major mental disorders: schizophrenia, major depression and bipolar disorder (manic depression). Respondents are considered to have a severe alcohol or other drug disorder if they have ever had a DIS diagnosis of cocaine, crack, or heroin abuse or dependence, or if they have had seven or more DIS alcohol symptoms (for example, the shakes). Otherwise, respondents are considered to have a moderate alcohol or other drug disorder if they ever met the DIS diagnosis of drug or alcohol abuse or dependence. We choose lifetime measures of major mental and substance use disorders, instead of current measures, because (1) lifetime alcohol and drug use are less likely to reflect recent labor market success and program participation, reducing potential endogeneity bias, (2) public programs provide services (including psychotropic drugs) that keep major mental disorders in remission, (3) the human capital and labor market effects from substance abuse may be long term. ${ }^{8,10}$ A poor work history, including inability to get along with coworkers or being fired for substance use, or an arrest record related to substance use, including driving while intoxicated, are probably barriers to employment.

The homeless population has a substantially higher prevalence of health problems and disabilities than the general (domiciled) population (Table 2).* Homeless individuals are three times as likely to report that they are in either poor or fair health. Twenty-three percent of the homeless persons in the sample have had a major mental health disorder

\footnotetext{
* Prevalence rates for the adult domiciled population aged 15 to 54 are from the National Comorbidity Survey. ${ }^{15-17}$ Health status of the adult domiciled population aged 18 to 64 is from the National Health Interview Survey, 1993. ${ }^{18}$
} 
Table 2. Health, mental health and substance use: comparison of homeless population to general population (percentage)

\begin{tabular}{lcc}
\hline & $\begin{array}{c}\text { Alameda } \\
\text { County } \\
\text { homeless } \\
\text { population }\end{array}$ & $\begin{array}{c}\text { National } \\
\text { domiciled } \\
\text { population }\end{array}$ \\
\hline Poor health & 9.2 & 2.7 \\
Fair health & 26.0 & 7.5 \\
Major mental disorder & 22.8 & 15.4 \\
Drug disorder & 56.7 & 11.9 \\
Alcohol disorder & 53.7 & 23.5 \\
Drug or alcohol disorder & 72.4 & 26.6 \\
Sample size & 471 & 8098 \\
\hline
\end{tabular}

Notes: For homeless population, diagnoses are for ever had an alcohol, drug and major mental disorder during the respondent's lifetime, based on the Diagnostic Interview Schedule. For domiciled population, diagnoses are for ever had an alcohol, drug, major depressive disorder, bipolar I and nonaffective psychosis during the respondent's lifetime, based on the Composite International Diagnostic Interview, population aged 15 to 54 .

Sources: Authors' calculations from the Survey of Alameda County Homeless People (Homeless Population), reports from the National Comorbidity Survey, ${ }^{15-17}$ and reports from the National Health Interview Survey. ${ }^{18}$

(schizophrenia, manic depression or major depression) at some point in their lifetime, compared with 15.4 percent for the general population. Most striking are the substantial problems associated with drugs and alcohol. Fully 72.4 percent of homeless people have had a drug or alcohol disorder, compared with only 26.6 percent of the general population. While alcohol or other drug problems are probably both a cause and a consequence of homelessness, these problems-along with mental health and physical health problems-limit the capacity of homeless people to work.

\section{Low Levels of Employment}

For homeless persons in this sample, we classify employment between the first and second waves into three categories: (1) never worked, (2) lower work level (half of or fewer days in the period or less than six hours per day when they worked) and (3) higher work level (more than half of the days in the period and six or more hours per day when they worked). Only 14 percent of the sample worked at the higher level over the six-month period. Another 34 percent worked at the lower level, and fully 52 percent did not work at all.* Employment in this sample is higher than a

* Both low numbers of days and shorter hours lead to the lower work level classification. Among persons who worked low levels between the first and second waves, 54 percent worked six or more hours but half or fewer days, 49 percent worked half or more days and less than six hours per day, and 7 percent worked few hours and few days.

To assess the stability of these levels of labor force participation, we compared labor force participation in the six months between waves 1 and 2 with labor force participation between waves 2 and 3. The persons who initially did not work at all were very unlikely to work (only 22.8 percent worked later). Among those who worked at the low level, 47.2 continued with this work level, and 38.4 percent did not work at all between waves 2 and 3. Among those with a higher employment level, 57.4 percent continued to participate at this level.
1987 national estimate that 6 percent of the homeless had steady employment and 25 percent had irregular work in the past month. ${ }^{19}$ The higher levels in this sample, however, may be due to the broader definitions used in our study. $\dagger$

During the period of the survey, the monthly unemployment rate in the Oakland Metropolitan Statistical Area (MSA) ranged from 4.8 to 6.3 percent, which was below the national rate. With the labor market opportunities available in Alameda County, the generally low level of employment among the homeless population may result from limited skills, abilities and capacity for work.

For those who worked at the lower level, the median monthly earned income was $\$ 169$. For the few who worked at the higher level, the median monthly income was $\$ 600$. The low earnings of workers with low levels of employment are probably a symptom of the spot labor market, where the minimum wage prevails and the daily supply of jobs is uncertain..$^{20}$

\section{Low Levels of Program Participation and Low Benefit Levels}

Program participation is measured by indicators for whether a person received, at any time between the first and second interviews: GA, Aid to Families with Dependent Children (AFDC) or federal disability benefits-SSI or Social Security Disability Insurance (SSDI), although nearly all received SSI alone.* Approximately 10 percent of the sample received AFDC, and another 10 percent of the sample received disability benefits. The average monthly cash benefit for SSI/DI was \$618; for AFDC, it was \$628. In terms of enrollment, GA was the largest program, with 40 percent of homeless adults receiving benefits. ${ }^{*}$ However, the mean GA cash benefit was only $\$ 322$, a substantially smaller amount than AFDC and disability benefits.

We also present eligibility and take-up rates (percent of those eligible who participate) in Table 3 for each of the public programs using simulated eligibility criteria. Overall, approximately 45 percent of potential eligibles for GA and AFDC participated in each of those programs. We simulated eligibility for SSI/DI by assuming those with a physical limitation, major depression, schizophrenia, bipolar disorder, or substance abuse of opioids, cocaine or crack would be eligible. $\neq$ Based on this assumption, 69 percent of the sample were eligible but only 14 percent of potentially eligible homeless persons participated. Take-up rates were much higher (29 percent) for those with a physical limitation than those with a major mental disorder and no physical

\footnotetext{
$†$ Differences in time frames, as well as differences between national and local labor and housing markets, also may contribute to the different levels of employment.

* Food stamp benefits averaged $\$ 85$ per month among the 37 percent of wave 1 respondents receiving benefits. These low benefits have a smaller role in total income.

** Those receiving disability or AFDC benefits are not eligible for GA. † As of 1 January 1997 persons whose disability was due only to a drug or alcohol disorder are no longer eligible for SSI participation.
} 
Table 3. Public program simulated eligibility and take-up rates by health, mental health and substance use

\begin{tabular}{|c|c|c|c|}
\hline & $\mathrm{GA}^{\mathrm{a}}$ & $\mathrm{SSI} / \mathrm{DI}^{\mathrm{b}}$ & $\mathrm{AFDC}^{\mathrm{c}}$ \\
\hline Eligibility rate (percent) & 79 & 69 & 21 \\
\hline \multicolumn{4}{|l|}{ Take-up rate (percent) } \\
\hline Total & 45 & 14 & 45 \\
\hline Physical limitation & 50 & 29 & 39 \\
\hline $\begin{array}{l}\text { Major mental disorder (no } \\
\text { physical disability) }\end{array}$ & 55 & 5 & 43 \\
\hline $\begin{array}{l}\text { Severe substance use } \\
\text { disorder (no physical or } \\
\text { mental disability) }\end{array}$ & 43 & 5 & 43 \\
\hline No disability or disorder & 40 & - & 54 \\
\hline Number of observations & 338 & 325 & 133 \\
\hline
\end{tabular}

${ }^{a}$ Excludes the 133 people homeless with children and/or pregnant (AFDC eligibles).

b325 persons with physical limitations or lifetime diagnoses of major mental illness or severe substance use disorders (opioids, cocaine or crack) were considered potentially eligible.

${ }^{\mathrm{c}} 133$ people homeless with children and/or pregnant.

disability (5 percent) and those with a severe substance use disorder only (5 percent).

Both the Alameda County GA program and the SSI program have tried to accommodate the needs of homeless recipients. Homeless GA recipients can have their checks sent to contracted check-cashing outlets and a few community-based organizations. Being domiciled is not a condition for GA recipiency. At the time of the survey, the county did not limit the length of time people could receive GA benefits. SSI checks can be sent to shelters, and emergency SSI benefit checks can be issued immediately. Nonetheless, qualitative information from interviews with sample members suggests that getting benefits often requires extraordinary persistence. ${ }^{3}$

Both the GA and SSI programs had restrictions on the behavior of recipients with substance use disorders at the time of the survey. The county required recipients with a self-reported substance use disorder to enroll in treatment. In 1991, at the start of the survey, only 20000 of the 4 million disabled SSI recipients were disabled due to a substance use disorder. Federal law at the time of the survey required that SSI recipients disabled because of substance use disorders be in treatment programs, and their benefits must be sent to a representative payee. ${ }^{21}$ The representative payee requirement was an effort to reduce the possibility that disability payments will be used to purchase drugs. There are no treatment or representative payee requirements for SSI beneficiaries with other disabling conditions who also have substance use disorders. As of 1 January 1997 persons with a substance use disorder only were no longer eligible for SSI benefits.

\section{Human Capital}

The human capital variables measure high school graduation, formal technical or vocational training and problems in communicating (either illiteracy or great difficulty hearing or understanding). Although high school graduation is prevalent (72 percent), 29 percent of the sample had at least one communication problem, such as illiteracy or great difficulty hearing or understanding.

\section{Other Variables}

We use a rich array of explanatory variables to examine other possible correlates of work and program participation. These variables are all taken from the responses to the first wave. We include several measures of family background and childhood experience-whether the person's mother (or other woman who raised the sample member) completed high school; whether the person was ever placed during childhood in foster care or a group home; whether the person was ever sentenced to a juvenile hall as a child; whether the person's parents ever received welfare while the person was a child, as a proxy for childhood poverty, and whether the person was physically or sexually abused as a child. Table 1 indicates the extraordinary prevalence of negative childhood experiences-22\% had suffered child abuse, $28 \%$ had been sentenced to juvenile halls and $10 \%$ were placed in foster care or group homes. Koegel et al. ${ }^{22}$ estimated the prevalence of some of these childhood experiences in the general population. They estimated 3.5 to 5.8 percent of the general adult population had experienced out-of-home placement as children, less than the rate of 10 percent in our sample of homeless adults. Rates of child abuse suffered by adult homeless persons in the sample are similar to the highest estimates of child abuse in the general population: 11 to 14 percent of the general population suffered physical abuse, and 10 to 22 percent of women and 3 to 8 percent of men suffered sexual abuse.

Demographic variables include age and indicators for whether the respondent was male, black, had children homeless with them, as married or had served time in prison. Eighteen percent of the respondents had served time in prison, which probably reduces employability.

\section{Analytical Procedures}

We seek to explain which homeless individuals are more likely to secure significant income through employment or participation in public programs. Employment and program participation are determined by human capital (skills for work), health status and disability, childhood experiences and other demographic factors, including those linked to program eligibility and discrimination. Childhood experience measures are included because they may affect the development and quality of human capital, social networks and psychological well-being. We expect more human capital and better health to be associated with greater levels of employment and less use of public transfer programs. People with poor childhood experience are expected to have lower work levels and greater participation in government transfer programs.

The models of employment status and program participation are recursive in that homelessness at the first wave 
of the survey is treated as given. Thus we explore whether, given their initial homelessness, persons can gain or maintain access to income. We study employment and program participation over a six-month period (on average) between waves 1 and 2, during which individuals move in and out of homelessness.

The models are also recursive in that the explanatory variables associated with employment status and program participation between waves 1 and 2 are taken from the wave 1 interview, thereby reducing endogeneity bias due to 'post-diction' problems. ${ }^{23}$ While variables such as race, sex and childhood experience should not change over time, employment and especially participation in public programs may affect health, mental health and substance abuse problems.

We estimate work and program participation regressions separately, because work and program participation are not necessarily exclusive activities for three reasons. First, a sample member may have both worked and participated in programs during the time between interviews, but not simultaneously. Second, the prevailing low level of work in this population would not exclude them from simultaneously receiving SSI, but it would reduce GA benefits. Third, on the other hand, stigma may account for persons not working and also not receiving benefits. ${ }^{24}$ Using a simultaneous model for all the choices would be infeasible because work and program participation are not mutually exclusive, some sample members are eligible for some programs but not others and the sample size is limited.

We estimate each equation separately by maximumlikelihood methods, as follows. Employment level is estimated by a generalized ordered logit model where the trichotomous variable (never worked, lower work level, higher work level) described earlier is the dependent variable. This model relaxes the proportionality assumption by estimating separate coefficients on the independent variables for lower and higher employment levels. Specifically,

$$
\operatorname{Prob}(\text { never worked })=F\left(-X^{\prime} \beta_{1}\right)
$$

Table 4. Employment generalized ordered logit regression results

\begin{tabular}{|c|c|c|c|c|c|c|}
\hline \multirow[b]{2}{*}{ Variable } & \multicolumn{2}{|c|}{ No work } & \multicolumn{2}{|c|}{ Lower work level } & \multicolumn{2}{|c|}{ Higher work level } \\
\hline & $\begin{array}{c}\text { Marginal } \\
\text { effect }\end{array}$ & $95 \% \mathrm{CI}$ & $\begin{array}{l}\text { Marginal } \\
\text { effect }\end{array}$ & $95 \% \mathrm{CI}$ & $\begin{array}{c}\text { Marginal } \\
\text { effect }\end{array}$ & $95 \% \mathrm{CI}$ \\
\hline \multicolumn{7}{|l|}{ Human capital } \\
\hline High school & -0.08 & $(-0.19,0.03)$ & 0.03 & $(-0.08,0.15)$ & 0.05 & $(-0.04,0.13)$ \\
\hline Technical education & 0.03 & $(-0.05,0.12)$ & -0.03 & $(-0.11,0.06)$ & -0.01 & $(-0.07,0.05)$ \\
\hline Communication problems & 0.07 & $(-0.03,0.16)$ & -0.002 & $(-0.10,0.10)$ & $-0.06^{*}$ & $(-0.14,0.01)$ \\
\hline \multicolumn{7}{|l|}{ Health status } \\
\hline Physical limitation & $0.12 * *$ & $(0.01,0.23)$ & -0.09 & $(-0.21,0.04)$ & -0.03 & $(-0.13,0.07)$ \\
\hline Poor health & 0.13 & $(-0.04,0.31)$ & -0.09 & $(-0.27,0.09)$ & -0.04 & $(-0.17,0.09)$ \\
\hline Fair health & $0.10 * *$ & $(0.01,0.20)$ & -0.01 & $(-0.11,0.09)$ & $-0.09 * *$ & $(-0.16,-0.02)$ \\
\hline Mental health & -0.07 & $(-0.17,0.03)$ & 0.05 & $(-0.06,0.16)$ & 0.02 & $(-0.06,0.10)$ \\
\hline AODA severe & $-0.14 * *$ & $(-0.24,-0.05)$ & $0.18^{* *}$ & $(0.09,0.28)$ & -0.04 & $(-0.12,0.04)$ \\
\hline AODA moderate & $-0.20 * *$ & $(-0.32,-0.09)$ & $0.29 * *$ & $(0.18,0.40)$ & $-0.09 * *$ & $(-0.16,-0.01)$ \\
\hline \multicolumn{7}{|l|}{ Childhood experience } \\
\hline Mother's education & $-0.09 *$ & $(-0.19,0.01)$ & 0.01 & $(-0.08,0.10)$ & $0.08^{* *}$ & $(0.01, .015)$ \\
\hline $\begin{array}{l}\text { Mother's education } \\
\text { missing }\end{array}$ & -0.06 & $(-0.20,0.08)$ & 0.04 & $(-0.13,0.20)$ & 0.02 & $(-0.12,0.17)$ \\
\hline Parent welfare & $0.15^{* *}$ & $(0.06,0.25)$ & $-0.10 * *$ & $(-0.19,-0.02)$ & -0.05 & $(-0.11,0.02)$ \\
\hline Child abuse & $-0.11 * *$ & $(-0.22,0.00)$ & 0.08 & $(-0.03,0.20)$ & 0.03 & $(-0.06,0.11)$ \\
\hline Juvenile hall & -0.06 & $(-0.16,0.05)$ & -0.01 & $(-0.12,0.09)$ & $0.07 *$ & $(-0.01,0.16)$ \\
\hline Foster care & 0.04 & $(-0.11,0.19)$ & -0.004 & $(-0.15,0.15)$ & -0.04 & $(-0.13,0.06)$ \\
\hline \multicolumn{7}{|l|}{ Demographic } \\
\hline Male & $-0.10^{*}$ & $(-0.22,0.02)$ & 0.06 & $(-0.06,0.18)$ & 0.05 & $(-0.04,0.13)$ \\
\hline Black & $0.08 *$ & $(-0.01,0.17)$ & 0.03 & $(-0.06,0.12)$ & $-0.11 * *$ & $(-0.19,-0.03)$ \\
\hline Age & 0.0035 & $(-0.002,0.009)$ & 0.00 & $(-0.005,0.005)$ & $-0.0035^{*}$ & $(-0.007,0.0003)$ \\
\hline With children & 0.02 & $(-0.14,0.19)$ & -0.09 & $(-0.25,0.07)$ & 0.07 & $(-0.08,0.21)$ \\
\hline Married & $-0.20 * *$ & $(-0.33,-0.06)$ & $0.15^{*}$ & $(-0.005,0.30)$ & 0.05 & $(-0.07,0.17)$ \\
\hline Prison & $0.10^{*}$ & $(-0.01,0.21)$ & -0.02 & $(-0.13,0.09)$ & $-0.08 * *$ & $(-0.15,-0.01)$ \\
\hline Average probability & 0.52 & & 0.34 & & 0.14 & \\
\hline Sample size & & & 471 & & & \\
\hline Log likelihood & & & -406.7 & & & \\
\hline
\end{tabular}

Notes: Low work level $=$ worked half or fewer days, or less than six hours per day when working. Higher work level $=$ worked more than half of the days and six or more hours per day. Discrete effects are reported for discrete explanatory variables. Marginal effects may not sum across work levels due to rounding. $\mathrm{AODA}=$ alcohol and other drug abuse.

$* p<.10$, ** $p<.05$. 
Table 5. Public program participation: probit regression results

\begin{tabular}{|c|c|c|c|c|}
\hline \multirow[b]{2}{*}{ Variable } & \multicolumn{2}{|c|}{ Disability Programs ${ }^{\mathrm{a}}$} & \multicolumn{2}{|c|}{ General Assistance $^{\mathrm{b}}$} \\
\hline & Marginal effect & $95 \% \mathrm{CI}$ & Marginal Effect & $95 \% \mathrm{CI}$ \\
\hline \multicolumn{5}{|l|}{ Human capital } \\
\hline High school & 0.04 & $(-0.03,0.12)$ & $0.11 *$ & $(-0.01,0.23)$ \\
\hline Technical education & 0.02 & $(-0.06,0.09)$ & 0.05 & $(-0.05,0.15)$ \\
\hline Communication problems & 0.04 & $(-0.04,0.13)$ & $0.12 * *$ & $(0.01,0.23)$ \\
\hline \multicolumn{5}{|l|}{ Health status } \\
\hline Physical limitation & $0.21 * *$ & $(0.11,0.31)$ & 0.03 & $(-0.11,0.16)$ \\
\hline Poor health & 0.002 & $(-0.10,0.11)$ & 0.16 & $(-0.05,0.36)$ \\
\hline Fair health & -0.04 & $(-0.12,0.03)$ & $0.15^{* *}$ & $(0.03,0.27)$ \\
\hline Mental health & -0.01 & $(-0.08,0.07)$ & 0.08 & $(-0.04,0.21)$ \\
\hline AODA severe & - & & $0.15 * *$ & $(0.03,0.26)$ \\
\hline AODA moderate & $-0.13 * *$ & $(-0.19,-0.07)$ & $0.29 * *$ & $(0.15,0.42)$ \\
\hline \multicolumn{5}{|l|}{ Childhood experience } \\
\hline Mother's education & 0.01 & $(-0.07,0.10)$ & 0.05 & $(-0.07,0.17)$ \\
\hline Mother's education missing & 0.03 & $(-0.10,0.15)$ & $0.19 * *$ & $(0.01,0.37)$ \\
\hline Parent welfare & 0.004 & $(-0.08,0.08)$ & 0.07 & $(-0.06,0.18)$ \\
\hline Child abuse & -0.03 & $(-0.11,0.04)$ & -0.001 & $(-0.14,0.14)$ \\
\hline Juvenile hall & 0.06 & $(-0.03,0.14)$ & -0.09 & $(-0.21,0.02)$ \\
\hline Foster care & 0.02 & $(-0.11,0.14)$ & -0.08 & $(-0.27,0.11)$ \\
\hline \multicolumn{5}{|l|}{ Demographic } \\
\hline Male & -0.06 & $(-0.16,0.04)$ & -0.05 & $(-0.21,0.11)$ \\
\hline Black & $-0.08^{*}$ & $(-0.16,0.01)$ & $0.17 * *$ & $(0.06,0.28)$ \\
\hline Age & $0.0042 * *$ & $(0.001,0.008)$ & $-0.0077 * *$ & $(-0.014,-0.002)$ \\
\hline Married & 0.04 & $(-0.09,0.16)$ & -0.09 & $(-0.32,0.14)$ \\
\hline Prison & 0.06 & $(-0.04,0.16)$ & 0.05 & $(-0.09,0.18)$ \\
\hline Average probability & 0.14 & & 0.45 & \\
\hline Sample size & \multicolumn{2}{|c|}{325} & \multicolumn{2}{|c|}{338} \\
\hline Log likelihood & \multicolumn{2}{|c|}{-97.7} & \multicolumn{2}{|l|}{-204.0} \\
\hline
\end{tabular}

Notes: Discrete effects are reported for discrete explanatory variables. AODA $=$ alcohol and other drug abuse.

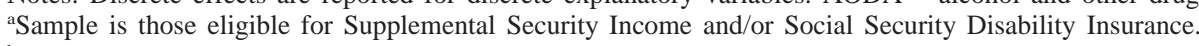

${ }^{\mathrm{b}}$ Sample excludes those eligible for Aid to Families with Dependent Children.

$* p<.10, * * p<.05$.

$$
\begin{aligned}
\operatorname{Prob}(\text { lower work level }) & =F\left(-X^{\prime} \beta_{2}\right)-F\left(-X^{\prime} \beta_{1}\right) \\
\operatorname{Prob}(\text { higher work level }) & =1-F\left(-X^{\prime} \beta_{2}\right)
\end{aligned}
$$

where $F$ is the logistic function. ${ }^{25,26} \mathrm{We}$ use this model because we first attempted to estimate an ordered logit model of labor force participation, where only the intercept varies across levels. However, we conducted an approximate maximum-likelihood test and rejected the hypothesis that the odds ratios are proportional for all choices $(p=0.04){ }^{27}$

For program participation, we focus on two government transfer programs: (1) disability benefits (SSI and/or SSDI) and (2) GA. Because only a small proportion of the sample is eligible for AFDC, estimates from a participation regression would not be reliable. Participation in disability programs and GA are estimated as probit models over the subsamples of potentially eligible participants. For the disability programs, only persons with physical disabilities or lifetime diagnoses of major mental illness or severe substance use disorders were considered potentially eligible. Lifetime diagnoses are relevant for program participation, because current remission may be temporary or the result of program participation. Nationally, few persons received disability benefits due to a substance use disorder at the time of the survey. ${ }^{21}$ The number of persons meeting disability eligibility criteria (325) is a large proportion of the sample.* Persons with children and pregnant women would be eligible for AFDC instead of GA, and so 133 people with children and/or pregnant were excluded from the GA regression.

For each regression, we calculated marginal effects for the continuous variable (age) and discrete effects for the indicator variables as the mean of the marginal or discrete effects for each sample member. Confidence intervals for the marginal and discrete effects were calculated using standard errors derived using the delta method. Note that in a generalized ordered logit model, the discrete (or marginal) effect of a variable on lower work level depends

\footnotetext{
* Applicants for SSI can receive GA while waiting for their disability determination (often lasting more than a year), and so a few persons in the sample received both between waves 1 and 2 . Early attempts at joint estimation of the two program participation equations (as a bivariate probit model) did not converge; this is probably related to the lack of exclusionary restrictions, but any such restrictions would be arbitrary in these data.
} 
Appendix Table A. Attrition probit results

\begin{tabular}{|c|c|c|}
\hline \multirow[b]{2}{*}{ Variable } & \multicolumn{2}{|c|}{ Attrition wave $1-2$} \\
\hline & Coefficient & $\begin{array}{c}\text { Standard } \\
\text { error }\end{array}$ \\
\hline \multicolumn{3}{|l|}{ Human capital } \\
\hline High school & -0.23 & 0.15 \\
\hline Technical education & 0.03 & 0.13 \\
\hline Communication problems & 0.09 & 0.15 \\
\hline \multicolumn{3}{|l|}{ Health status } \\
\hline Physical limitation & $0.36 * *$ & 0.17 \\
\hline Poor health & -0.12 & 0.26 \\
\hline Fair health & -0.15 & 0.17 \\
\hline Mental health & 0.16 & 0.17 \\
\hline AODA severe & $-0.58 * *$ & 0.16 \\
\hline AODA moderate & $-0.40 * *$ & 0.20 \\
\hline \multicolumn{3}{|l|}{ Childhood experience } \\
\hline Mother's education & $-0.39 * *$ & 0.15 \\
\hline Mother's education missing & 0.12 & 0.20 \\
\hline Parent welfare & -0.19 & 0.15 \\
\hline Child abuse & -0.13 & 0.18 \\
\hline Juvenile hall & 0.04 & 0.16 \\
\hline Foster care & -0.26 & 0.26 \\
\hline \multicolumn{3}{|l|}{ Demographic } \\
\hline Male & $0.36^{*}$ & 0.21 \\
\hline Black & -0.12 & 0.14 \\
\hline Age & -0.01 & 0.01 \\
\hline With children & $-0.71 *$ & 0.38 \\
\hline Married & -0.21 & 0.29 \\
\hline Prison & 0.18 & 0.17 \\
\hline Constant & 0.14 & 0.39 \\
\hline Sample size & \multicolumn{2}{|c|}{560} \\
\hline Log likelihood & \multicolumn{2}{|c|}{-242.0} \\
\hline
\end{tabular}

Note: AODA $=$ alcohol and other drug abuse.

$* p<.10, * * p<.05$.

on the variable's coefficients for both lower and higher work levels, so the sign and magnitude of the discrete effect does not necessarily correspond to the coefficient for lower work level. Therefore, we present the marginal and discrete effects and their confidence intervals in the tables, and the regression coefficients in Appendix Tables B and C.

\section{Results}

\section{Employment Results}

The results of the employment generalized ordered logit regression indicate that many problems of homeless persons have large negative estimated effects on employment (Table 4). Drug and alcohol abuse and dependence are positively associated with lower work level but are negatively related to higher work level and no work. The severe and moderate measures of abuse/dependence are associated with 0.18 and 0.29 , respectively, greater probability of lower work level. Moderate abuse/dependence is associated with a 0.09 lower probability of higher work level, while the estimated effect of severe abuse/dependence is not statistically significant.
One possible explanation for the different effects on lower and higher work levels is that substance users work at lower levels to be able to purchase drugs or alcohol, but are not able to work on a consistent basis. The estimated effects of severe mental health are not significant, and they are small relative to the confidence intervals.

Other health problems are associated with less work. Physical disabilities are associated with a 0.12 greater probability of not working. Fair health is associated with a 0.09 lower probability of higher work level and a 0.10 greater probability of not working. Poor health is also negatively, but not significantly, associated with both lower and higher work level. The sample size is relatively small, so the confidence intervals for the marginal effects are fairly wide.

Among the human capital variables, only the negative effects of communication problems on higher work level are statistically significant at the 10 percent level. Those with communication problems have a 0.06 lower probability of higher level work. The small sample size produces wide confidence intervals, but the estimated effects of high school graduation have the expected signs.

Most of the childhood experience variables have statistically significant marginal estimates. Having a mother who graduated from high school is associated with a 0.08 greater probability of higher work level and a 0.09 lower probability of not working. Parental receipt of welfare, a proxy for childhood poverty, is associated with a 0.10 lower probability of lower work level and a 0.15 greater probability of not working. Having been abused as a child is associated with a 0.11 lower probability of not working. Having been placed in a juvenile hall as a child is associated with a higher work level.

The estimated effects of the demographic variables are consistent with patterns one would expect in the domiciled population. Men have a 0.10 lower probability of not working. Being black is associated with a 0.08 higher probability of not working, and a 0.11 lower probability of higher work level. Being older is negatively associated with a higher work level. Being married is positively and strongly associated with working, and probably reflects the characteristics of these people that made them more desirable for marriage. Having served a prison sentence is significantly associated with a lower probability of higher work levels (0.08 lower probability) and with a higher probability of not working. This association probably reflects employers' unwillingness to hire former convicts, or perhaps the attitudes of former prisoners.

\section{Disability Program Results}

Among persons we include as potentially eligible for the federal disability programs, the primary determinants of recipiency are disabilities, substance use, race and age (Table 5). There are clearly different effects for different types of disability. Having a physical disability is associated with a 0.21 greater probability of participating in the disability programs than those having severe substance 
Appendix Table B. Employment: generalized ordered logit regression coefficients

\begin{tabular}{|c|c|c|c|c|c|}
\hline \multirow[b]{2}{*}{ Variable } & \multicolumn{2}{|c|}{ Lower work level } & \multicolumn{2}{|c|}{ Higher work level } & \multirow{2}{*}{$\begin{array}{c}\text { Joint } \\
\text { significance }\end{array}$} \\
\hline & Coefficient & Standard error & Coefficient & Standard error & \\
\hline \multicolumn{6}{|l|}{ Human capital } \\
\hline High school & 0.39 & 0.27 & 0.43 & 0.44 & \\
\hline Technical education & -0.17 & 0.21 & -0.08 & 0.28 & \\
\hline Communication problems & -0.32 & 0.24 & -0.61 & 0.39 & \\
\hline \multicolumn{6}{|l|}{ Health status } \\
\hline Physical limitation & $-0.57 * *$ & 0.27 & -0.30 & 0.50 & \\
\hline Poor health & -0.66 & 0.44 & -0.42 & 0.73 & \\
\hline Fair health & $-0.51^{*}$ & 0.25 & $-0.91 * *$ & 0.41 & $* *$ \\
\hline Mental health & 0.34 & 0.26 & 0.17 & 0.35 & \\
\hline AODA severe & $0.71 * *$ & 0.25 & -0.35 & 0.36 & $* *$ \\
\hline AODA moderate & $1.03 * *$ & 0.33 & $-0.90 *$ & 0.46 & $* *$ \\
\hline \multicolumn{6}{|l|}{ Childhood experience } \\
\hline Mother's education & 0.44 & 0.24 & $0.75^{* *}$ & 0.35 & $*$ \\
\hline Mother's education missing & $0.29 *$ & 0.36 & 0.19 & 0.60 & \\
\hline Parent welfare & $-0.74 * *$ & 0.23 & -0.45 & 0.32 & $* *$ \\
\hline Child abuse & $0.55 * *$ & 0.28 & 0.22 & 0.35 & \\
\hline Juvenile hall & 0.28 & 0.26 & $0.59 *$ & 0.34 & \\
\hline Foster care & -0.20 & 0.38 & -0.35 & 0.50 & \\
\hline \multicolumn{6}{|l|}{ Demographic } \\
\hline Male & $0.51 *$ & 0.30 & 0.43 & 0.43 & \\
\hline Black & $-0.40^{*}$ & 0.23 & $-0.90 * *$ & 0.30 & $* *$ \\
\hline Age & -0.02 & 0.01 & $-0.03 *$ & 0.02 & \\
\hline With children & -0.11 & 0.41 & 0.53 & 0.53 & \\
\hline Married & $1.01 * *$ & 0.38 & 0.42 & 0.46 & $* *$ \\
\hline Prison & $-0.49 *$ & 0.29 & $-0.85^{*}$ & 0.46 & $*$ \\
\hline Constant & -0.07 & 0.65 & -0.53 & 0.82 & \\
\hline Sample size & \multicolumn{5}{|c|}{471} \\
\hline Log likelihood & \multicolumn{5}{|c|}{-406.7} \\
\hline
\end{tabular}

Notes: Low work level $=$ worked half or fewer days, or less than six hours per day when working. Higher work level $=$ worked more than half of the days and six or more hours per day. Omitted category is no work. AODA $=$ alcohol and other drug abuse.

a Joint hypothesis tests of whether the variables affect both levels of work using a joint test of the coefficients.

$* p<.10, * * p<.05$.

disorders (the omitted category). The estimated effect of major mental disorders is negative but close to zero, indicating no statistically significant difference between the effect of major mental disorders and the effect of severe substance use disorders. By extension, among those potentially eligible, having a physical disability is associated with a 0.22 greater probability of participating in federal disability programs than those with major mental disorders-mirroring the takeup rates shown in Table 3 .

Among persons otherwise eligible for disability benefits, having a moderate substance use disorder (which we assume would not in itself have qualified an individual for disability benefits prior to 1 January 1997) is a significant barrier to recipiency; moderate substance use disorders are associated with a 0.13 lower likelihood of receiving disability benefits. A moderate substance use disorder may affect the ability to navigate the program bureaucracy. In addition, many shelters prohibit drug and alcohol use while on premises, inhibiting users from using shelter services, including help with getting on assistance programs.

None of the estimated marginal effects of the human capital variables are statistically significant, and the point estimates imply small marginal effects on the probability of participation. However, the small sample size leads to large confidence intervals around these estimated marginal effects. The same holds true for the childhood experience variables.

Among the demographic variables, being black is associated with a 0.08 lower probability of participation in federal disability programs. Older persons are significantly more likely to receive benefits. This is consistent with ability to engage in manual labor decreasing with age. In addition, older persons may be more likely to be eligible for the SSDI program (which generally requires 40 quarters of work experience) than the SSI program.

\section{GA Results}

GA is the benefit program of last resort, and the probit results are consistent with this programmatic function. Persons with problems that may not qualify as disabilities are more likely to participate in GA. Communication problems are associated with a 0.12 greater probability of 


\begin{tabular}{|c|c|c|c|c|}
\hline \multirow[b]{2}{*}{ Variable } & \multicolumn{2}{|c|}{ Disability programs ${ }^{a}$} & \multicolumn{2}{|c|}{ General Assistance $^{\mathrm{b}}$} \\
\hline & Coefficient & Standard error & Coefficient & Standard error \\
\hline \multicolumn{5}{|l|}{ Human capital } \\
\hline High school & 0.26 & 0.25 & $0.34 *$ & 0.19 \\
\hline Technical education & 0.10 & 0.22 & 0.14 & 0.15 \\
\hline Communication problems & 0.26 & 0.23 & $0.36 * *$ & 0.17 \\
\hline \multicolumn{5}{|l|}{ Health status } \\
\hline Physical limitation & $1.08 * *$ & 0.24 & 0.08 & 0.20 \\
\hline Poor health & 0.01 & 0.32 & 0.46 & 0.31 \\
\hline Fair health & -0.27 & 0.25 & $0.43 * *$ & 0.18 \\
\hline Mental health & -0.04 & 0.24 & 0.24 & 0.19 \\
\hline AODA severe & - & - & $0.43 * *$ & 0.18 \\
\hline AODA moderate & $-1.20 * *$ & 0.50 & $0.85 * *$ & 0.23 \\
\hline \multicolumn{5}{|l|}{ Childhood experience } \\
\hline Mother's education & 0.07 & 0.26 & 0.14 & 0.18 \\
\hline Mother's education missing & 0.15 & 0.36 & $0.54 *$ & 0.28 \\
\hline Parent welfare & 0.02 & 0.23 & 0.19 & 0.17 \\
\hline Child abuse & -0.22 & 0.27 & -0.003 & 0.21 \\
\hline Juvenile hall & 0.32 & 0.24 & -0.27 & 0.18 \\
\hline Foster care & 0.11 & 0.36 & -0.23 & 0.29 \\
\hline \multicolumn{5}{|l|}{ Demographic } \\
\hline Male & -0.33 & 0.27 & -0.14 & 0.23 \\
\hline Black & $-0.43^{*}$ & 0.23 & $0.49 * *$ & 0.17 \\
\hline Age & $0.03 * *$ & 0.01 & $-0.02 * *$ & 0.01 \\
\hline Married & 0.21 & 0.34 & -0.27 & 0.35 \\
\hline Prison & 0.33 & 0.25 & 0.13 & 0.20 \\
\hline Constant & $-2.50 * *$ & 0.66 & -0.64 & 0.48 \\
\hline Sample size & \multicolumn{2}{|c|}{325} & \multicolumn{2}{|c|}{338} \\
\hline Log likelihood & \multicolumn{2}{|c|}{-97.7} & \multicolumn{2}{|c|}{-204.0} \\
\hline
\end{tabular}

Note: $A O D A=$ alcohol and other drug abuse.

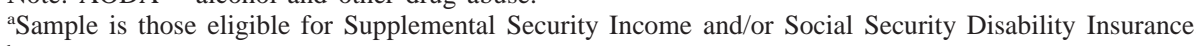

${ }^{\mathrm{b}}$ Sample excludes those eligible for Aid to Families with Dependent Children.

$* p<.10, * * p<.05$.

participating in GA. Fair health is associated with a 0.15 greater probability of GA participation relative to those in good or excellent health. The estimated effect of poor health implies a similarly greater probability of participation, but the confidence interval is quite wide. Persons reporting fair or poor health may have health problems that are not sufficiently disabling to qualify them for disability benefits, but that do inhibit work.

Despite GA's substance use treatment requirements, persons with such disorders are more likely to participate, again because their conditions limit work but may not be categorized as disabling conditions, depending on the severity. Moderate substance use disorders are associated with a 0.29 greater probability of participating in GA, while severe substance use disorders are associated with a 0.15 greater probability of participating.

The results also suggest that some skill is required to enter and remain in the program: having a high school diploma is associated with a 0.11 greater probability of GA participation.

Other factors have statistically significant estimated marginal effects. Black individuals are more likely to receive
GA, which is consistent with their lower probability of working at higher levels. Older persons are less likely to participate in GA; they seem to receive disability benefits instead. Only one childhood experience variable is significantly associated with greater GA participation: an indicator for the respondent not knowing whether the woman who raised the respondent finished high school. It is unclear what, if anything, this result indicates.

\section{Conclusion}

Our results indicate that mental health and disability play a large role in the employment and program participation of the homeless and persons at risk for homelessness. We find that physical disabilities are a barrier to employment. We also find that those with substance use disorders are most likely to work at lower levels that provide less income. With respect to government transfer programs, we find low rates of participation and that these rates vary considerably by type of disability. In particular, those with a physical disability are much more likely than those with a mental disorder to participate in the federal disability programs 
(SSI/DI), but, among the homeless, the disability programs have the lowest participation rate of the government transfer programs. In addition, those with substance use disorders were less likely to participate in the federal disability programs and more likely to participate in the much less generous GA program, which provides low income. Ironically, the federal disability program, through the Medicaid program, provides greater access to substance abuse treatment.

With the low rates of employment and high rates of physical, mental health and substance-use-related disabilities, government transfer programs are especially important for the homeless population as a source of income support. The low rates of participation, particularly for the federal disability programs, suggest the need for continued research in improving access to income support programs among eligible homeless populations. Our study was limited to one site, so there is limited variation in the characteristics of the programs. Therefore, we could not examine how the rules and regulations of AFDC and GA, or local variations in administration of SSI/DI programs help or hinder the participation of homeless people, because there was no variation within the programs. A multisite study could examine how programs might be made more accessible to homeless people.

Finally, changes in public program rules concerning persons with substance use disorders and problems has the potential to impact the well-being of homeless persons and persons at risk for homelessness. Our results suggest that the effect of removing substance use disorders (as of 1 January 1997) as eligible disabilities for the SSI/DI programs may be small for those already homeless - few of those eligible for SSI/DI because of a substance use disorder participated-but may put those persons at risk for homelessness.

Changes in GA program eligibility and other rules have a potentially larger impact on homeless persons-more than two-thirds have a drug or alcohol disorder and many rely on GA programs for income. We find that those with a drug or alcohol disorder are more likely to participate in GA programs and less likely to participate in more generous programs such as SSI/DI (even if eligible because of a physical or mental disability). As GA programs adopt more restrictive policies towards persons with drug and alcohol problems (or eliminate eligibility altogether), this cashassistance program of last resort may no longer be available to many homeless persons who rely on it.

\section{Acknowledgements}

We thank Irv Piliavin and Irene Wong for the data, suggestions and comments; participants of the health economics seminar at the University of Wisconsin-Madison and two anonymous reviewers for comments; and Millicent Henderson of the Alameda County Social Service Agency for information on the General Assistance program. The research was supported in part by a training grant from the National Institute of Mental Health. The views expressed in this paper are those of the authors, and no official endorsement by the US Agency for Healthcare Research and Quality or the US Department of Health and Human Services in intended or should be inferred.

\section{References}

1. Zlotnick C, Robertson MJ. Sources of income among homeless adults with major mental disorders or substance use disorders. Psychiatr Serv 1996; 47 (2): 147-151.

2. Jencks C. The Homeless. Cambridge, MA: Harvard University Press, 1994.

3. Wright BRE. Pathways off the streets: homeless people and their use of resources. Focus 1997; 19 (1): 70-74.

4. Robertson MJ, Zlotnick C, Westerfelt A. Drug use disorders and treatment contact among homeless adults in Alameda County, California. Am J Public Health 1996; 87 (2): 221-228.

5. North CS, Smith EM. A systematic study of mental health services utilization by homeless men and women. Soc Psychiatry Psychiatr Epidemiol 1993; 28: 77-83.

6. Padgett D, Struening EL, Andrews H. Factors affecting the use of medical, mental health, alcohol, and drug treatment services by homeless adults. Med Care 1990; 28 (3): 805-821.

7. Koegel P, Burnam MA, Farr RK. The prevalence of specific psychiatric disorders among homeless individuals in the inner city of Los Angeles. Arch Gen Psychiatry 1988; 45: 1085-1092.

8. Buchmueller TC, Zuvekas SH. Drug use, drug abuse, and labor market outcomes. Health Econ 1998; 7 (3): 229-245.

9. Ettner SL, Frank RG, Kessler RC. The impact of psychiatric disorders on labor market outcomes. Indust Labor Relations Rev 1997; 51 (1): 64-81.

10. Mullahy J, Sindelar JL. Alcoholism, work, and income. J Labor Econ 1993; 11 (3): 494-520.

11. Wolfe BL, Hill SC. The effect of health on the work effort of single mothers. J Human Resources 1996; 30 (1): 42-62.

12. Piazza T, Cheng Y-T. Sample Design for the Study of Alameda County Residents. Berkeley, CA: University of California, Survey Research Center, 1992.

13. American Psychiatric Association (APA). Diagnostic and Statistical Manual of Mental Disorders 3rd edn (revised). Washington, DC: APA, 1987.

14. Robins LN et al. Validity of the diagnoses. Diagnostic Interview Schedule, Version II: DSM-III. Psychol Med 1982; 12: 855-870.

15. Kessler, RC et al. Lifetime and 12-month prevalence of DSM-III-R psychiatric disorders in the United States: results from the National Comorbidity Survey. Arch Gen Psychiatry 1994; 51: 8-19.

16. Kessler, RC et al. Comorbidity of DSM-III-R major depressive disorder in the general population: results from the US National Comorbidity Survey. Br J Psychiatry 1996; 168 (Suppl. 30): 17-30.

17. Kessler, RC et al. The epidemiology of DSM-III-R bipolar I disorder in a general population survey. Psychol Med 1997; 27 (5): 1079-1089.

18. Benson, V, Marano MA. Current estimates from the National Health Interview Survey, 1993. National Center for Health Statistics. Vital Health Stat 1995; 10 (190).

19. Burt M. Over the Edge: The Growth of Homelessness in the 1980s. New York: Sage, 1989.

20. Weigand RB. Sweat and blood: Sources of income on a southern skid row. In Homelessness in the United States. New York: Greenwood, 1990; 111-122.

21. US Committee on Ways and Means. 1994 Green Book. Washington, DC: US Government Printing Office, 1994.

22. Koegel P, Melamid E, Burnam MA. Childhood risk factors for homelessness among homeless adults. Am J Public Health 1995; 85 (3): 1642-1649.

23. Manning WG, Newhouse JP, Ware JE. 1981. The status of health in demand estimation; or beyond excellent, good, fair, poor. In Economic Aspects of Health. Chicago: University of Chicago Press, 143-184.

24. Moffitt R. An economic model of welfare stigma. Am Econ Rev 1983; 73: 1023-1035.

25. Fu VK. Estimating generalized ordered logit models. Stata Tech Bull Reprints 1998; 8: 160-164.

26. Peterson B, Harrell FE Jr. Partial proportional odds models for ordinal response variables. Appl Stat 1990; 39: 205-217.

27. Wolfe R, Gould W. An approximate likelihood ratio test for ordinal response models. Stata Tech Bull Reprints 1998; 7: 199-204. 